\title{
Overexpression of IFITM1 Has Clinicopathologic Effects on Gastric Cancer and Is Regulated by an Epigenetic Mechanism
}

\author{
Jieun Lee, ${ }^{*}$ Sung-Ho Goh, ${ }^{\dagger}$ Naaleum Song, ${ }^{*}$ \\ Jung-Ah Hwang, ${ }^{*}$ Seungyoon Nam, ${ }^{*}$ II Ju Choi, ${ }^{\neq}$ \\ Aesun Shin, ${ }^{\S}$ In-Hoo Kim, ${ }^{\natural} \mathrm{Mi}-\mathrm{Ha}$ Ju, \\ Jin Sook Jeong," and Yeon-Su Lee*

\begin{abstract}
From the Branches of Cancer Genomics, ${ }^{*}$ New Experimental Therapeutics, ${ }^{\dagger}$ Gastric Cancer, ${ }^{\ddagger}$ Molecular Epidemiology, ${ }^{\S}$ and Molecular Imaging and Therapy, "Research Institute, National Cancer Center, Goyang Gyeonggi-do; and the Department of
\end{abstract} \\ Pathology," Dong-A University College of Medicine, Busan, South \\ Korea
}

In an effort to identify novel genes related to the prognosis of gastric cancer, we performed gene expression profiling and found overexpressed levels of human interferon-induced transmembrane protein 1 (IFITM1). We validated the gastric cancer-specific up-regulation of IFITM1 and its association with cancer progression. We also studied its epigenetic regulation and tumorigenesisrelated functions. Expression of IFITM1 was evaluated in various human gastric cancer cells and in 35 patient tumor tissues by quantitative RT-PCR and Western blot analyses. The results showed highly up-regulated IFITM1 in cancer cell lines and tissues. Furthermore, IHC studies were performed on 151 patient tissues, and a significant correlation was revealed between higher IFITM1 expression and Lauren's intestinal type $(P=0.007)$ and differentiated adenocarcinoma $(P=0.025)$. Quantitative studies of DNA methylation for $27 \mathrm{CpG}$ sites in the regulatory region showed hypermethylation in cells expressing low levels of IFITM1. Methylation-dependent IFITM1 expression was confirmed further by in vitro demethylation using 5-aza2 '-deoxycytidine and luciferase assays. The functional analysis of IFITM1 by silencing of its expression with small-interfering RNA showed decreased migration and invasiveness of cancer cells, whereas its overexpression exhibited the opposite results. In this study, we demonstrated gastric cancer-specific overexpression of IFITM1 regulated by promoter methylation and the role of IFITM1 in cancer prognosis. (Am J Pathol 2012, 181:43-52; bttp:// dx.doi.org/10.1016/j.ajpath.2012.03.027)
Gastric cancer is one of the most common human cancers. In 2008, there were approximately 989,600 new cases and 738,000 deaths worldwide. ${ }^{1}$ The most important prognostic indicator for patients with gastric cancer is the observation of metastasis to lymph nodes or distant organs since this occurs in $80 \%$ to $90 \%$ of patients in the United States and Europe. ${ }^{2}$ Although many studies are currently ongoing, reliable molecular biomarkers of gastric cancer that can help predict tumor progression or assist in extending the survival of patients are yet to be established.

Recently developed technologies, such as gene expression profiling, have been applied toward the identification of genes and genetic alterations associated with the development of gastric cancer, potentially serving as biomarkers for the diagnosis and prognosis of patients with cancer. ${ }^{3-5}$ Several novel genes and polymorphisms associated with cancer prognosis have been revealed by recent studies using these methods. ${ }^{6-8}$ Not only genetic alternations but also epigenetic modifications are involved in tumorigenesis, and many researchers have reported the cancer-specific epigenetic regulation in human cancer. ${ }^{9-11}$ For example, methylation of $\mathrm{CpGs}$, especially in the promoter region, has been suggested as a possible factor influencing the activity of gastric cancer-related genes. ${ }^{12,13}$

From a previous gene expression profiling study of human gastric tumor and normal tissues (GSE30727),

Supported by intramural research grants from the National Cancer Center (NCC 0710660 and NCC 1110040) and by a Korea Science and Engineering Foundation grant from the Korean government (Ministry of Education, Science, and Technology) (R13-2002-044-05001-0).

Accepted for publication March 15, 2012.

J.L. and S.-H.G. contributed equally to this work.

CME Disclosure: The authors of this article and the planning committee members and staff have no relevant financial relationships with commercial interest to disclose.

Supplemental material for this article can be found at http://ajp. amjpathol.org or at http://dx.doi.org/10.1016/j.ajpath.2012.03.027.

Address reprint requests to Yeon-Su Lee, Ph.D., Cancer Genomics Branch, Research Institute, National Cancer Center, 323 Ilsan-ro, Goyang Gyeonggi-do, 410-769, South Korea; or Jin Sook Jeong, M.D., Ph.D., Department of Pathology, Dong-A University College of Medicine, Busan, 602-714, South Korea. E-mail: yslee2@ncc.re.kr or jsjung1@dau.ac.kr. 
we identified interferon-induced transmembrane protein 1 (IFITM1) as an up-regulated gene in tumors. Additional surveys of public databases [ArrayExpress (http://www.ebi.ac.uk/arrayexpress), European Bioinformatics Institute (http://www.ebi.ac.uk), and Gene Expression Omnibus (http://www.ncbi.n/m.nih.gov/geo)] also showed its up-regulated expression in diverse cancer cell lines. IFITM1 (alias Leu13 or 9-27) is a cell surface $17-\mathrm{kDa}$ membrane protein that is encoded on chromosome arm 11p15.5. It is a member of the interferoninduced transmembrane protein family and was initially known to be a leukocyte antigen that is part of a membrane complex involved in the transduction of antiproliferative and homotypic adhesion signals in lymphocytes. ${ }^{14-16}$ In humans, the IFITM family consists of at least three other functional genes (IFITM1, IFITM2, and IFITM3), and IFITM1 has been studied for its involvement in the inhibition of viral replication, ${ }^{17}$ promotion of cell invasion, ${ }^{18}$ and drug response. ${ }^{19}$ Furthermore, recent studies suggest an association between IFITM1 and several cancers, such as head and neck cancer, ${ }^{18}$ serous ovarian cancer, ${ }^{20}$ leukemia and lymphoma, ${ }^{21}$ and cervical squamous cell carcinoma. ${ }^{22}$ Although one study indicated that IFITM1 may modulate the invasiveness of gastric cancer cells, ${ }^{23}$ no further results were reported, and so the role of IFITM1 and its regulation in gastric cancer is not fully clarified.

In this study, we report the up-regulation of IFITM1 expression in gastric cancer and the correlation of IFITM1 expression with clinicopathologic features of patients with gastric cancer. In addition, the promoter CpG methylation analysis revealed that IFITM1 expression is epigenetically regulated. The in vitro functional study showed the effect that IFITM1 exerts on cell migration and invasion of gastric cancer cells. Here, we propose that IFITM1 could be a good candidate as a potential target in the therapy of gastric cancer.

\section{Materials and Methods}

\section{Cell Cultures and Tissue Samples}

All the cell lines were obtained from ATCC (Manassas, VA) or the Korean Cell Line Bank (Seoul, South Korea) and were cultured in the designated media (Thermo Scientific HyClone, Logan, UT) supplemented with $10 \%$ fetal bovine serum (Thermo Scientific HyClone) and 1\% penicillin-streptomycin (Invitrogen, Carlsbad, CA). HMECs were obtained from Lonza Inc. (Walkersville, MD) and were cultured in

Table 1. Characteristics of the 151 Patients with Gastric Cancer Who Contributed Tissue for These Studies

\begin{tabular}{|c|c|c|c|c|c|}
\hline \multirow[b]{2}{*}{ Characteristic } & \multicolumn{4}{|c|}{ IFITM1 expression* } & \multirow[b]{2}{*}{$P$ value } \\
\hline & Negative $(n=18)$ & Mild $(n=66)$ & Moderate $(n=50)$ & Marked $(n=17)$ & \\
\hline Sex & & & & & 0.5848 \\
\hline Male & 11 & 46 & 37 & 10 & \\
\hline Female & 7 & 20 & 13 & 7 & \\
\hline Age (years) & & & & & 0.3026 \\
\hline$<60$ & 10 & 36 & 25 & 5 & \\
\hline$\geq 60$ & 8 & 30 & 25 & 12 & \\
\hline Differentiation & & & & & $0.0250^{\dagger}$ \\
\hline Well & 0 & 16 & 11 & 6 & \\
\hline Moderately & 4 & 23 & 21 & 7 & \\
\hline Poorly & 14 & 27 & 18 & 4 & \\
\hline Lauren's classification & & & & & $0.0068^{\dagger}$ \\
\hline Intestinal & 2 & 37 & 29 & 11 & \\
\hline Mixed & 5 & 9 & 10 & 4 & \\
\hline Diffuse & 11 & 20 & 11 & 2 & \\
\hline LVI & & & & & 0.2080 \\
\hline Negative & 11 & 47 & 26 & 11 & \\
\hline Positive & 7 & 19 & 24 & 6 & \\
\hline T classification & & & & & 0.1264 \\
\hline T1 & 6 & 29 & 16 & 4 & \\
\hline T2 & 3 & 16 & 7 & 5 & \\
\hline T3 & 6 & 10 & 11 & 1 & \\
\hline T4 & 3 & 11 & 16 & 7 & \\
\hline LN metastasis & & & & & 0.1141 \\
\hline Negative & 8 & 39 & 22 & 5 & \\
\hline Positive & 10 & 27 & 28 & 12 & \\
\hline TNM stage & & & & & 0.7857 \\
\hline I & 6 & 36 & 20 & 7 & \\
\hline II & 5 & 12 & 10 & 4 & \\
\hline III & 5 & 11 & 13 & 5 & \\
\hline IV & 2 & 7 & 7 & 1 & \\
\hline
\end{tabular}

Data are given as number of patients.

*For IFITM1 expression, negative, mild, moderate, and marked were determined according to the immunostaining intensity, and positive cases were categorized.

$+P<0.05$

¥Sixth edition of the American Joint Cancer Committee/Union Internationale Contre le Cancer.

LN, Iymph node; LVI, Iymphovascular invasion. 
MEGM basal medium (Lonza Inc.) supplemented with supplement reagent and growth factors. All human cell lines were grown in a $5 \% \mathrm{CO}_{2}$-humidified incubator at $37^{\circ} \mathrm{C}$.

Thirty-five pairs of normal and gastric carcinoma tissues used in quantitative RT-PCR (RT-qPCR), RT-PCR, and Western blot studies were obtained by endoscopic biopsy from patients after obtaining their informed consent; the protocols were approved by the Institutional Review Board of the National Cancer Center, Goyang Gyeonggi-do, South Korea (see Supplemental Table S1 at $h$ ttp://ajp.amjpathol. org). For immunohistochemical studies, tissues from 151 patients who had undergone gastrectomy and were diagnosed as having tubular adenocarcinoma at the Dong-A University Hospital, Busan, South Korea, between January 1, 2005, and October 31, 2005, were investigated (Table 1). All the patients signed an Institutional Review Board-approved written informed consent form.

\section{$R T$-qPCR and RT-PCR}

Total RNA purified using TRIzol reagent (Invitrogen) was reverse transcribed to cDNA using SuperScript III Reverse Transcriptase (Invitrogen) and was subjected to relative quantification of IFITM1 mRNA by quantitative reverse transcription normalized with glyceraldehyde-3-phosphate dehydrogenase (GAPDH) or $\beta$-2-microglobulin. ${ }^{24}$ The primers used are listed in Table 2. QuantiFast SYBR green PCR master mix (Qiagen Inc., Valencia, CA) was used in the LightCycler 480 system (Roche Applied Science, Mannheim, Germany). RT-PCR was performed using Taq DNA polymerase (SolGent Co. Ltd., Daejeon, South Korea).

\section{Western Blot Analysis}

Immunoblotting was performed using anti-IFITM1 (sc66827; Santa Cruz Biotechnology, Santa Cruz, CA), antiFLAG antibody (F7425; Sigma-Aldrich, St. Louis, MO), and anti- $\beta$-actin (Abcam Inc., Cambridge, MA). The signal intensity was measured after subtracting the background by using Multi Gauge V3.0 software (Fujifilm, Tokyo, Japan).

\section{Immunohistochemical Analysis of Gastric Carcinoma Tissues}

Immunohistochemical detection of IFITM1 was performed on three core cancer tissues and nonneoplastic gastric mucosa specimens ( $2 \mathrm{~mm}$ in diameter) for each individual. Tissues were arranged as arrays of $4.5-\mu \mathrm{m}$ sections mounted on silicon-coated glass slides with antiIFITM1 antibody (sc-66827; Santa Cruz Biotechnology) in the BenchMark XT automated system (Ventana Medical Systems Inc., Tucson, AZ) as described previously. ${ }^{25}$ Negative or positive controls were determined by immunostaining intensity of gastric carcinoma cells, and positive cases were categorized into mild, moderate, and marked expression. None of the patients had received any preoperative treatments. Outcomes were determined from the date of surgery until death or December 31, 2009, which resulted in follow-up of 0.8 to 59.8 months (mean, 48.9 months). We determined postoperative pathologic stage using the sixth edition of the American Joint Cancer Committee/Union Internationale Contre le Cancer classification system. ${ }^{26}$

Table 2. Primers Used in this Study

\begin{tabular}{|c|c|c|}
\hline Experiment & Primer ID & Sequence \\
\hline RT-qPCR & $\begin{array}{l}\text { IFITM1-Q-F } \\
\text { IFITM1-Q-R } \\
\text { GAPDH-F } \\
\text { GAPDH-R } \\
\text { B2M-F } \\
\text { B2M-R }\end{array}$ & $\begin{array}{l}\text { 5'-ACTAGTAGCCGCCCATAGCC-3' } \\
\text { 5'-GCACGTGCACTTTATTGAATG-3' } \\
\text { 5'-TGCACCACCAACTGCTTA-3' } \\
\text { 5'-GGATGCAGGGATGATGTTC-3' } \\
\text { 5'-ACTGAATTCACCCCCACTGA-3' } \\
\text { 5' -CCTCCATGATGCTGCTTACA-3' }\end{array}$ \\
\hline RT-PCR & $\begin{array}{l}\text { TNF- } \alpha-F \\
\text { TNF- } \alpha-R \\
\text { IL-6-F } \\
\text { IL-6-R } \\
\text { IL-8-F } \\
\text { IL-8-R }\end{array}$ & $\begin{array}{l}\text { 5'-AAGAATTCAAACTGGGGCCT-3' } \\
\text { 5'-GGCTACATGGGAACAGCCTA-3' } \\
\text { 5'-GAACTCCTTCTCCACAAGCG-3' } \\
\text { 5'-TTTTCTGCCAGTGCCTCTTT-3' } \\
\text { 5'-TAGCAAAATTGAGGCCAAGG-3' } \\
\text { 5'-GGACTTGTGGATCCTGGCTA-3' }\end{array}$ \\
\hline \multirow[t]{3}{*}{$\begin{array}{r}\text { EpiTYPER } \\
\text { analysis }\end{array}$} & $\begin{array}{l}\text { IFITM1-01-10-F } \\
\text { IFITM1-01-10-R }\end{array}$ & $\begin{array}{l}\text { 5'-AGGAAGAGAGTATGATTTTTGTGTTTGAGGGTTTT-3' } \\
\text { 5'-CAGTAATACGACTCACTATAGGGAGAAGGCTCTAATAACCAAAATTTCCTACCCCA-3' }\end{array}$ \\
\hline & $\begin{array}{l}\text { IFITM1-02-10-F } \\
\text { IFITM1-02-10-R } \\
\text { IFITM1-03-10-F } \\
\text { IFITM1-03-10-R }\end{array}$ & $\begin{array}{l}\text { 5'-AGGAAGAGAGTTTTTTGTGTATTTTTTGGTTTTGG-3' } \\
\text { 5'-CAGTAATACGACTCACTATAGGGAGAAGGCTAAAAAACCTCTCTCCTTAACCTTCA-3' } \\
\text { 5'-AGGAAGAGAGTTTGGGTTAATGGATAGTTAGGGAT-3' } \\
\text { 5'-CAGTAATACGACTCACTATAGGGAGAAGGCTCCAAAACCAAAAAATACACAAAAAA-3' }\end{array}$ \\
\hline & $\begin{array}{l}\text { IFITM1-04-10-F } \\
\text { IFITM1-04-10-R }\end{array}$ & $\begin{array}{l}\text { 5'-AGGAAGAGAGGGTTATGAGGATGTTTAGAATTAGGG-3' } \\
\text { 5' - CAGTAATACGACTCACTATAGGGAGAAGGCTAACTCACAAATAACTTCACCCCATA-3' }\end{array}$ \\
\hline \multirow[t]{3}{*}{ MSP analysis } & IFITM1-Meth-F & 5'-GAGATTTTCGTGTTCGATTATGTC-3' \\
\hline & $\begin{array}{l}\text { IFITM1-Meth-R } \\
\text { IFITM1-UnMeth-F }\end{array}$ & $\begin{array}{l}\text { 5'-ATAAAACCCCAAACTCACCG-3' } \\
5^{\prime} \text {-AGATTTTTGTGTTTGATTATGTTGT-3' }\end{array}$ \\
\hline & IFITM1-UnMeth-R & 5'-ATAAAACCCCAAACTCACCAAC-3' \\
\hline \multirow[t]{2}{*}{ Promoter assay } & IFITM1-C1-F(-750) & $5^{\prime}$ - GGGGTACCGTGGCACATGTGTGCCCTG-3' \\
\hline & $\begin{array}{l}\text { IFITM1-C2-F(-200) } \\
\text { IFITM1-C1C2-R(-1) }\end{array}$ & $\begin{array}{l}\text { 5'-GGGGTACCTGGCTAATTCACCAATTTACAAACAGC-3' } \\
5^{\prime} \text {-CCAAGCTTCTTCTGGCTTTGGGGAAGGAAG-3' }\end{array}$ \\
\hline
\end{tabular}

B2M, $\beta$-2-microglobulin. 
Quantitative Methylation and MethylationSpecific PCR Analysis and 5-Aza-dC Treatment

Genomic DNA extracted from the cell lines using the DNeasy kit (Qiagen Inc.) was sodium bisulfite treated using the EZ DNA Methylation-Gold kit (Zymo Research Corp., Orange, CA). Primers for EpiTYPER and methylation-specific PCR (MSP) analysis were designed using EpiDesigner software (Sequenom Inc., San Diego, CA) and are presented in Table 2. The methylation level was analyzed using EpiTYPER software (Sequenom Inc.). For MSP, genomic DNA was bisulfite modified and amplified using HotStarTaq DNA polymerase (Qiagen Inc.) using MSP primers. For demethylation by 5-azacytidine treatment, cells were seeded 24 hours before treatment and were incubated in media containing $20 \mu \mathrm{mol} / \mathrm{L}$ 5-aza- $2^{\prime}$ deoxycytidine (5-aza-dC; Sigma-Aldrich) for 3 days; the medium was changed every 24 hours and harvested for further analysis. For methylation analysis by cloning and sequencing, the promoter CpG site 10-15-contained region was amplified by PCR and was cloned into the pGEM-T easy vector system (Promega Corp., Madison, $\mathrm{WI}$ ). The sequences of the PCR products were analyzed using a 3730xI DNA analyzer (Applied Biosystems, Foster City, CA).

\section{Promoter Assay Using the Luciferase System}

The amplified fragments of the IFITM1 promoter region (construct 1: -200 to -1 , and construct 2: -750 to -1 from the start ATG codon; the primer sequences are presented in Table 2) were cloned into the pGL3-basic vector containing the firefly luciferase gene (Promega Corp.). For in vitro methylation, the promoter was treated

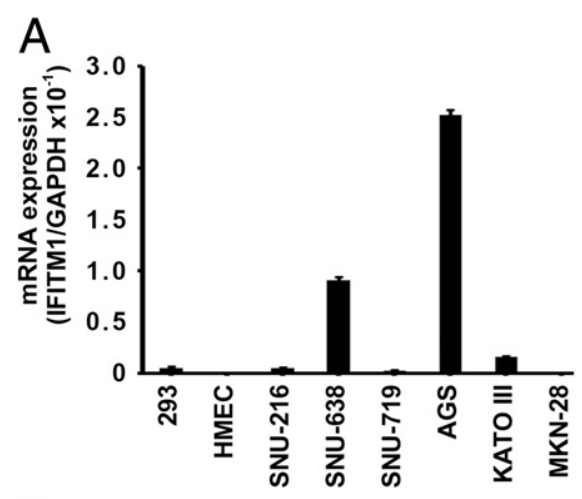

C

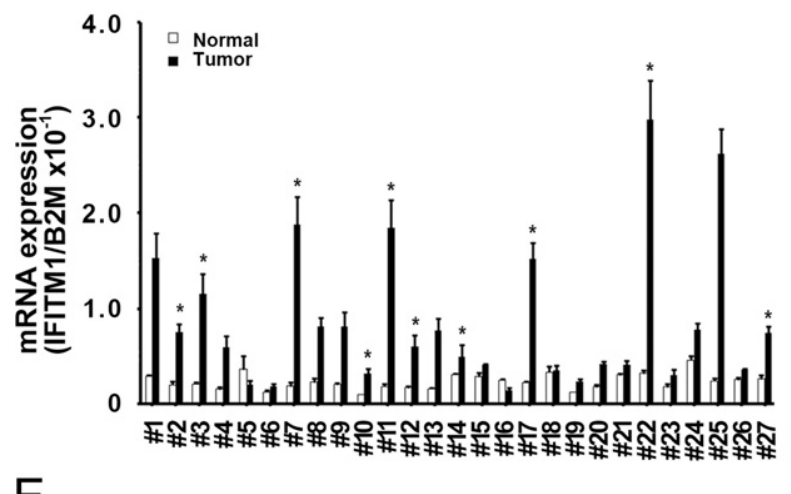

B
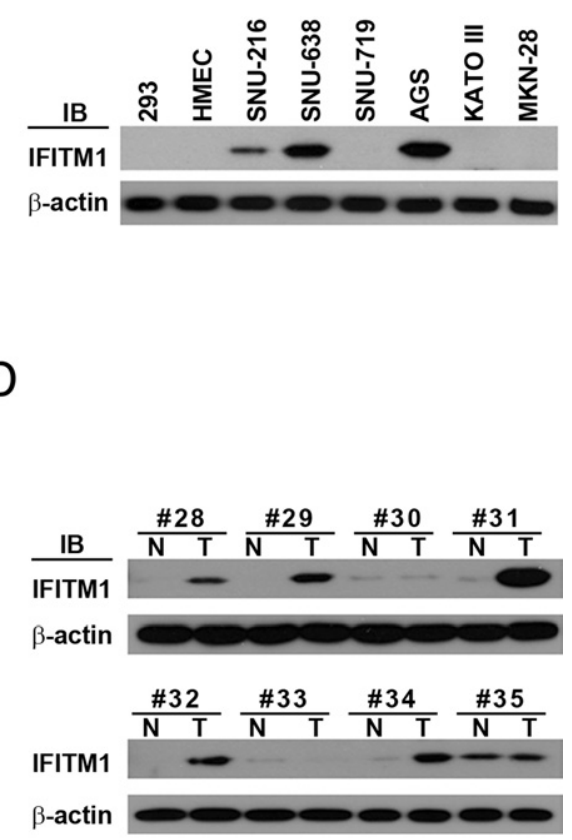

$\mathrm{E}$

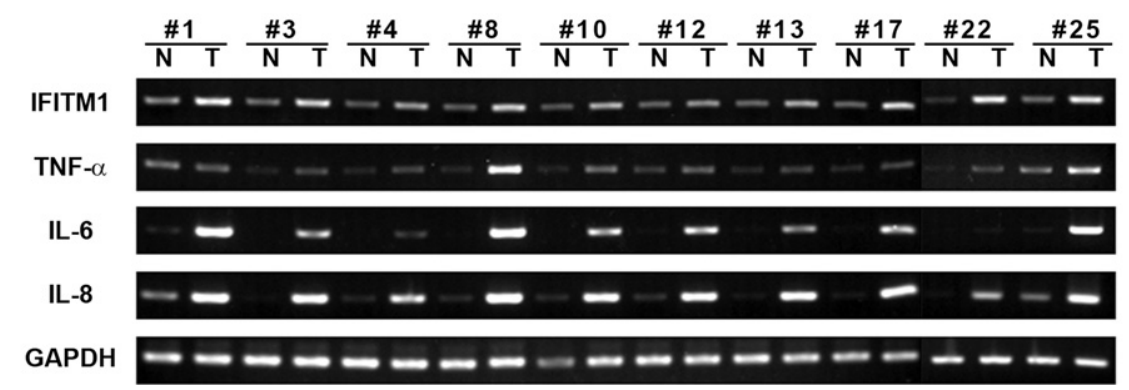

Figure 1. Up-regulation of IFITM1 in human gastric cancer cell lines and tissues. A: Mean \pm SD IFITM1 mRNA expression in two noncancer cell lines (293 and HMEC) and six gastric cancer cell lines (SNU-216, SNU-638, SNU-719, AGS, KATO III, and MKN-28) detected by RT-qPCR. B: Western blot analysis of IFITM1 protein in cell lines. $\beta$-actin was used as loading control. IB, immunoblotting. C: Mean \pm SD IFITM1 mRNA expression is detected in 27 pairs of matched gastric cancer tissues. Asterisks indicate intestinal-type gastric cancer tissues. B2M, $\beta$-2-microglobulin. D: Western blot analysis of IFITM1 protein levels in eight pairs of matched normal (N) and tumor (T) gastric cancer tissues. E: IFITM1, TNF- $\alpha$, IL-6, and IL-8 mRNA expression detected by RT-PCR in matched normal (N) and tumor (T) stomach tissues. 
with insert fragments with SssI CpG methylase (New England Biolabs, Ipswich, MA) and were religated. H23 human lung cancer cells $\left(2 \times 10^{5}\right)$ and each construct $(1 \mu \mathrm{g})$ were co-transfected with $10 \mathrm{ng}$ of pRL-CMV vector and Renilla luciferase as internal control for the transfection efficiency assessment, and 24 hours later, the luciferase activities were measured using the Dual-Luciferase reporter assay system (Promega Corp.).

\section{Silencing of IFITM1 Expression}

For the silencing of IFITM1 expression, $1.5 \times 10^{5}$ AGS human gastric cancer cells were transfected using smallinterfering RNA (siRNA) specific for human IFITM1 (SI00054117; 5'-ACAGTCTACCATATTATGTTA-3') or nontargeting siRNA (NC) (Qiagen Inc.) in a 6-well plate and were checked every 24 hours by Western blot analysis.

\section{Construction of IFITM1 Expression Clone and Transfection}

Human IFITM1 open reading frame isolated by PCR using forward primer 5'-GAATTCCACCCTTCCCCAAAGCCAGAAGATG-3' and reverse primer 5'-GGATCCAGTGCAAAGGTTGCAGGCTA-3' (Bioneer Corp., Daejeon, South Korea) was cloned into pFLAG-CMV-2 vector (Sigma-Aldrich) to make pFLAG-CMV2-IFITM1. This construct was transfected into 293 cells using Lipofectamine 2000 (Invitrogen).

\section{In Vitro Migration, Invasion, and Wound-Healing Assay}

Transfilter migration and invasion assays were performed using 8.0- $\mu \mathrm{m}$ pore inserts in a 24-well Transwell (Corning Inc., Corning, NY). For this assay, AGS cells were transfected with IFITM1 siRNA or NC siRNA for 2 days, or IFITM1-overexpressing 293 cells were seeded after 1 day of incubation. They were isolated and added to the upper chamber of a Transwell with a noncoated filter in the migration assay. The invasion assay was performed using 10\% Matrigel (BD Bioscience, San Jose, CA)-coated filters at $5 \times 10^{4}$ cells per well, and the cells were allowed to incubate for 48 hours. The migrating and invading cells were stained with Diff-Quik (using a staining kit from Sysmex Corp., Kobe, Japan). For wound measuring, a scratch on complete confluence was made, and the percentage of cell-free area at 24 hours was measured relative to the distance at 0 hour (100\%) using photographed images. Each experiment was performed in triplicate, and mean values are presented.

\section{Statistical Analysis}

The $t$-test was used to evaluate the significance of the difference between two groups. The $\chi^{2}$ test was conducted to determine the significance of the difference between the covariates. Survival durations were calculated via the Kaplan-Meier method. The log-rank test was used to compare cumulative survival in the patient

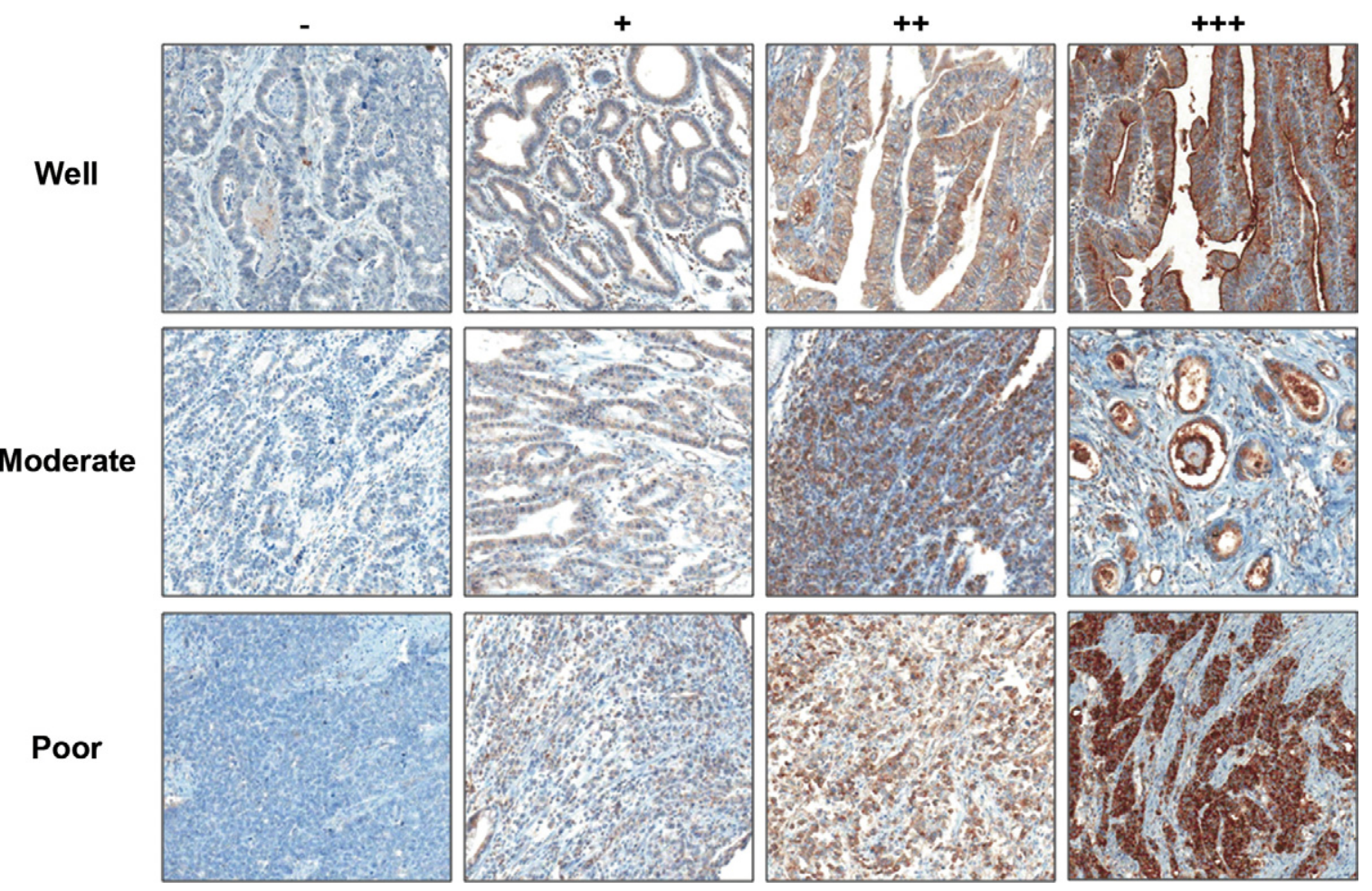

Figure 2. Immunohistochemical analysis of IFITM1 expression in well, moderately, and poorly differentiated human gastric adenocarcinomas. IFITM1 (brown) is mostly expressed in cytoplasms with mild $(+)$, moderate $(++)$, and marked $(+++)$ staining intensities. Negative specimens $(-)$ are denoted. IFITM1 was occasionally co-expressed at luminal borders, particularly in well-differentiated adenocarcinomas. Original magnification, $\times 200$. 
groups. We applied $P<0.05$ for the consideration of statistical significance throughout the study. The MedCalc software program (version 11.4; MedCalc Software, Mariakerke, Belgium) was used for the analyses.

\section{Results}

\section{Up-Regulation of IFITM1 in Human Gastric Cancer Cells and Tissues}

IFITM1 mRNA and protein expressions in six human gastric cancer cell lines (SNU-216, SNU-638, SNU-719, AGS, KATO III, and MKN-28) and two human noncancer cell lines (293 and HMEC) were analyzed by RT-qPCR and Western blot analysis. We found that the expressions of IFITM1 mRNA (Figure 1A) and IFITM1 protein (Figure 1B) were significantly higher in AGS and SNU-638 cell lines than in normal cell lines. The IFITM1 expressions in terms of protein level in gastric cancer cell lines were correlative to the mRNA level (Figure 1B).

In parallel studies of IFITM1 mRNA and protein expressions in 27 pairs of gastric cancer tissues and matched normal tissues, IFITM1 was highly up-regulated in 25 of 27 cancer tissues $(92.6 \%)$ compared with in their normal counterparts (paired $t$-test $P<0.001$ ) (Figure 1C). The mRNA expression levels of IFITM1 in 10 intestinaltype (Lauren's classification) tumor tissues showed a much higher elevation (5.7-fold increase in average) than in its normal counterpart. In accordance with the mRNA level difference, the protein levels in the paired patient tissues also showed an elevation in most cancer tissues (five of eight patients; 62.5\%) compared with in its normal counterpart $(P=0.008,3.4$-fold increase in average) (Figure 1D).

Since IFITM1 is an inflammation-inducible gene, the higher level of IFITM1 in some cancer tissues may reflect increased inflammation in these tissues. We, therefore, compared the expression of IFITM1 with that of other inflammation marker genes, including tumor necrosis factor- $\alpha$ (TNF- $\alpha$ ), IL-6, and IL-8. In the 10 patients showing increased IFITM1expression (fold change $>3$ times), IL-6 and IL-8 levels also increased, although TNF- $\alpha$ level was not correlated with IFITM1 expression (Figure 1E). These results suggest that up-regulation of IFITM1 expression levels in cancer reflect increased inflammatory responses.

\section{Clinicopathologic and Prognostic Significance of IFITM1 Expression}

One hundred thirty-three of 151 patients (88.1\%) showed positive IFITM1 expression in gastric adenocarcinomas. Mostly, IFITM1 was expressed in cytoplasms and occasionally was co-expressed at luminal borders, especially in well-differentiated adenocarcinomas (Figure 2; see also Supplemental Figure S1 at http://ajp.amjpathol.org). Although detected in infiltrating mononuclear leukocytes, nonneoplastic gastric epithelial cells did not express IFITM1. The characteristics of the 151 patients examined are presented in Table 1. Increased IFITM1 expression was more frequent in histologically differentiated gastric carcinomas $(P=0.025)$. In particular, the intestinal type (by Lauren's classification) showed a higher proportion of moderate or marked IFITM1 expression $(P=0.007)$, which is in accordance with mRNA expression analyzed by RT-qPCR. Patients with gastric carcinoma with moderate and marked expression of IFITM1 were found to have poorer survival than those with its negative and mild expression, even though this difference was not statistically significant $(P=0.086)$ (see Supplemental Figure S2 at http:// ajp.amjpathol.org).

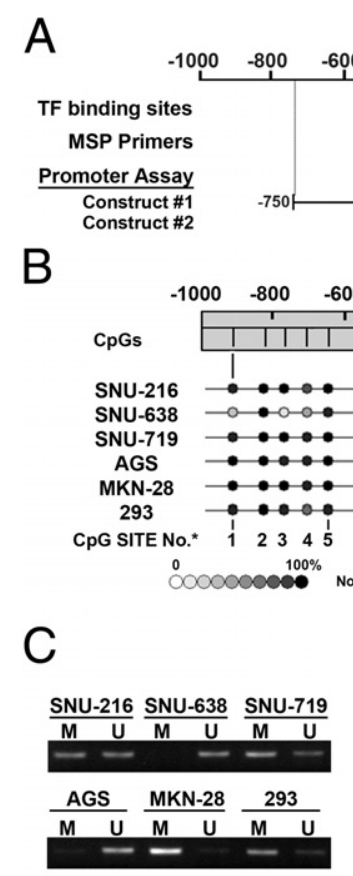

E

\section{D}

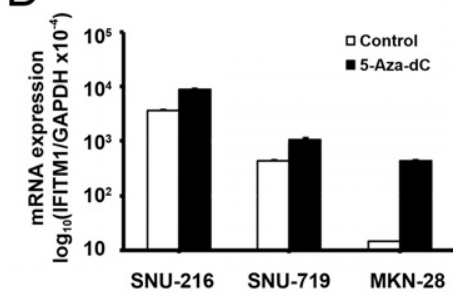

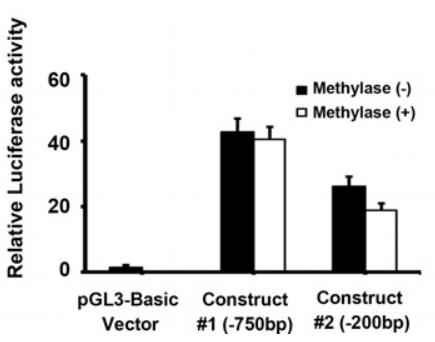

Figure 3. CPG methylation status of the IFITM1 gene promoter region in cell lines. A: Schematic view of the IFITM1 gene upstream region from -1000 to 400 of the start codon (ATG). ETS factor (ETSF) and cyclin D binding myb-like transcription factor (DMTF) transcription factor (TF) binding sites are indicated under the scale. Positions of primers for MSP and promoter constructs for luciferase assay are also placed on the map. B: Quantitative methylation analysis of CPG sites in IFITM1 promoter. CpG sites are depicted as a vertical bar in the map (see Supplemental Figure S3 at bttp:/lajp. amjpathol.org). C: MSP analysis of the IFITM1 gene promoter region in six cell lines. The methylated (M) and unmethylated (U) DNA was amplified by specific primers for each methylation status. D: Mean \pm SD levels of IFITM1 before and after 5-aza-dC treatment in gastric cancer cell lines SNU-216, SNU-719, and MKN-28. E: Promoter activity analysis of the IFITM1 gene by the measurement of mean \pm SD luciferase activity. 


\section{Quantitative Methylation Analysis of IFITM1 and Validation by MSP}

DNA methylation levels of IFITM1 were determined in five gastric cancer cell lines and one normal cell line covering $27 \mathrm{CpG}$ sites over the promoter, exon 1, and intron 1 regions (Figure $3 \mathrm{~A}$; also see the detailed $\mathrm{CpG}$ sites in Supplemental Figure S3 at http://ajp.amjpathol.org). In the vicinity of the transcriptional start site, high IFITM1-expressing gastric cancer cell lines (SNU-638 and AGS) showed low methylation compared with the normal cell line (293) and the low IFITM1-expressing gastric cancer cell lines (SNU-216, SNU-719, and MKN-28) (Figure 3B). Although CpG sites 1 to 5 seemed to be unrelated to gene expression, the methylation status of $\mathrm{CpG}$ sites 11 to 26 inversely correlated with IFITM1 gene expression, indicating promoter methylation-regulated gene expression.

Based on the results of the quantitative methylation analysis, primers were designed to target four CpG sites (No. 12, 13, 19, and 20). Although there was significant methylation of the four CpG sites in cells expressing low levels of IFITM1 (SNU-216, SNU-719, MKN-28, and 293), there was little methylation of these $\mathrm{CpG}$ sites in cells highly expressing IFITM1 (SNU-638 and AGS) (Figure $3 \mathrm{C})$. Therefore, these results suggest that the vicinity of the transcriptional start site region in the IFITM1 promoter, especially CpG sites 12 and 13, may play an important role in the regulation of methylation-related expression of IFITM1. When we searched the transcription factor binding sites of this region using Matlnspector analysis software (Genomatix Software $\mathrm{GmbH}$, Munich,
Germany), the predicted binding site of the human protooncogene ETS factor and cyclin D binding myb-like transcription factor, were found situated in the exact position of CpG site 12, with core similarity of 1.0 for all and matrix similarity of 0.946 and 0.874 , respectively (see Supplemental Figure S3 at http://ajp.amjpathol.org).

\section{Analysis of Methylation-Dependent IFITM1 Expression}

We examined whether DNA demethylation by 5-aza-dC treatment affected IFITM1 mRNA expression. 5-Aza-dCtreated SNU-216, SNU-719, and MKN-28 gastric cancer cells showed a greater increase in IFITM1 mRNA expression compared with in controls, as judged by RT-qPCR analysis (2.5-, 2.5-, and 30.3-fold increases, respectively) (Figure 3D). These results suggest that DNA methylation suppresses IFITM1 gene expression and that demethylation increases it.

Methylation-dependent IFITM1 expression was further confirmed by in vitro methylation studies in which two promoter constructs ( 1 : -750 to -1 , and 2: -200 to -1 ; Figure $3 \mathrm{~A}$ ) were methylated by methyltransferase and ligated to a luciferase reporter gene. Comparison of the luciferase activity of the methylated and unmethylated IFITM1 promoter showed an approximately $28 \%$ decrement in the case of construct 2 (Figure 3E), suggesting that the methylation status of the -200 to -1 promoter region (containing $\mathrm{CpG} 10$ to 15 ) is important for the regulation of IFITM1 expression.
A

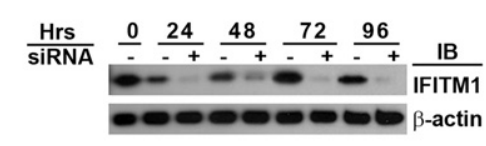

C
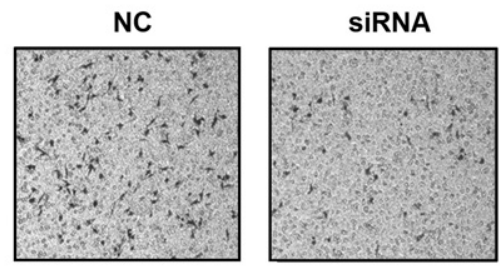

D
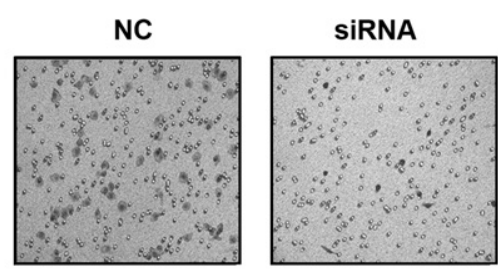

B
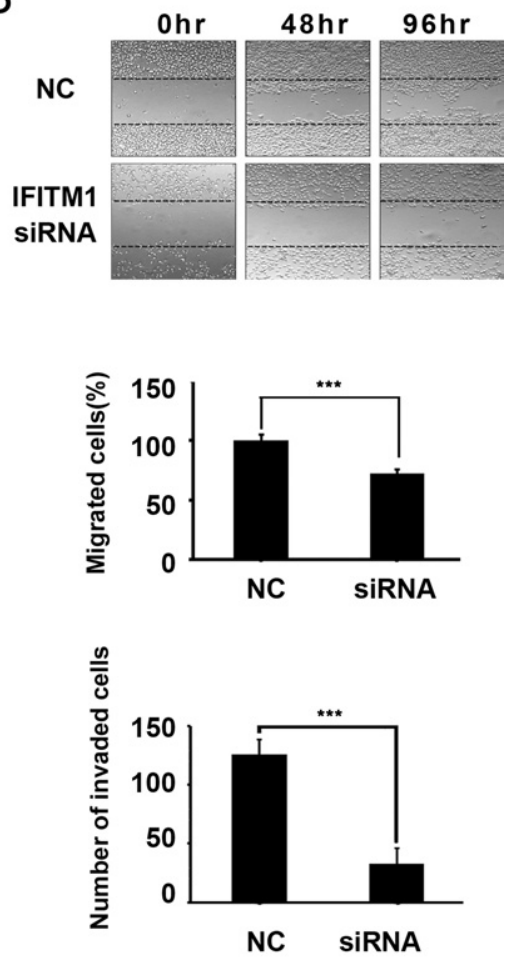

Figure 4. Effect of IFITM1 silencing on gastric cancer cell migration and invasion in vitro. A: Western blot analysis detecting the silencing of IFITM1 protein expression in AGS cells by nontargeting siRNA (NC) or IFITM1 siRNA transfection. IB, immunoblotting. B: IFITM1 siRNAtransfected AGS cells display considerably inhibited wound-healing capabilities compared with NC-transfected AGS cells. C: IFITM1 siRNAtransfected AGS cell migration capability is inhibited by approximately $28 \%$ compared with NC-transfected AGS cells. Mean \pm SD migrated cell percentages 24 hours after incubation are shown on the right ( $\mathrm{NC}=100 \%, n=3$ ). D: IFITM1 siRNA treatment dramatically inhibits the invasion of gastric cancer cells by approximately $74 \%$ compared with NC-transfected AGS cells. Mean \pm SD invaded cell numbers 48 hours after incubation are shown on the right $(n=3)$. **:e $P<0.001$. 
A

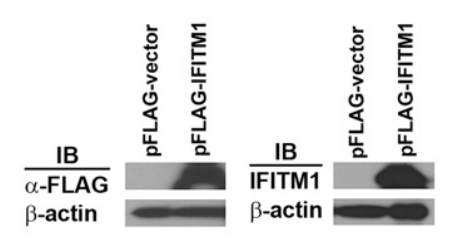

B

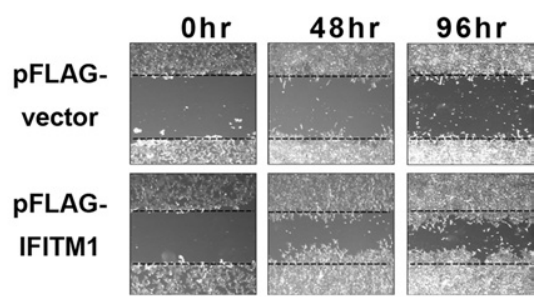

C
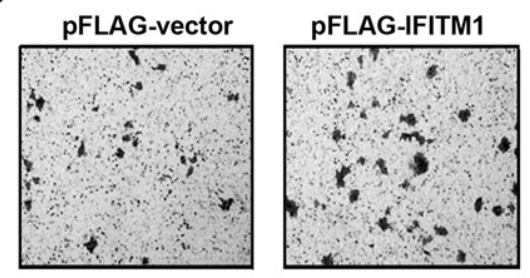

D

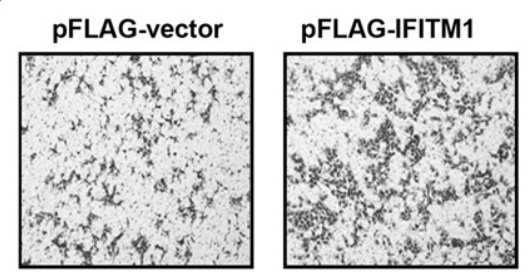

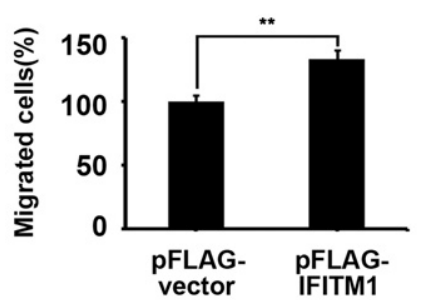

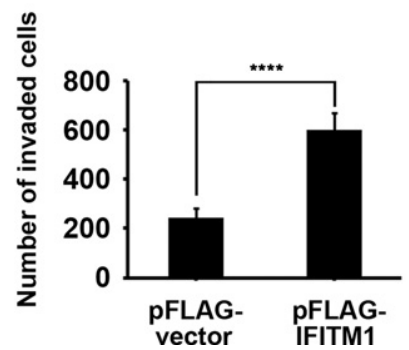

Figure 5. Effect of IFITM1 overexpression on cell migration and invasion. A: pFLAG-CMV2IFITM1-transfected 293 cells effectively produced IFITM1 protein. IB, immunoblotting. B: Wound-healing is enhanced by IFITM1 overexpression in 293 cells. C: Migration of 293 cells is enhanced by IFITM1 overexpression $(n=3)$. Data are given as mean \pm SD. D: In vitro invasion assay shows that IFITM1 overexpression dramatically enhances the invasion of 293 cells by approximately 2.5 -fold $(n=3)$. Data are given as

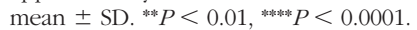

\section{IFITM1 Expression Affects Cell Migration and Invasion}

To investigate the role of IFITM1 in the progression of malignancy, we examined the influence of IFITM1 on the migration and invasion of AGS cells. We verified that IFITM1 expression is reduced by siRNA in AGS cells 24 hours after siRNA transfection and remains reduced for 96 hours. Nontargeting siRNA (NC) had no effect on IFITM1 mRNA or protein levels (Figure 4A). At 96 hours, wound healing of IFITM1 siRNA-transfected cells was inhibited (Figure 4B). The cell migration or invasion counted from 10 randomly selected areas per well at 24 hours showed that IFITM1 siRNA also inhibited migration (Figure 4C) and invasion (Figure 4D) remarkably.

We also confirmed that overexpression of IFITM1, conversely, enhances invasion and migration. When the pFLAG-CMV2-IFITM1 construct was transfected into 293 cells (Figure 5A), IFITM1 overexpression enhanced wound healing (Figure 5B), migration (Figure 5C), and invasion of cells (Figure 5D). Taken together, these results suggest that the expression of IFITM1controls the invasiveness and migration of gastric cancer.

\section{Discussion}

A previous study of human gastric cancer using microarray analysis identified differentially expressed genes, including IFITM1. The increased expression of IFITM1 reported for cancers of the cervix, ${ }^{22}$ colon, ${ }^{27}$ esophagus, ${ }^{28}$ and ovary ${ }^{29}$ strongly suggest the association of IFITM1 with tumorigenesis. The present data from numerous gastric cancer cell lines and many patient samples confirm that IFITM1 plays a role in gastric cancer tumorigenesis.

An interesting result from this study is that the IFITM1 expression level is markedly different in the intestinal and diffuse types of gastric cancer, with the intestinal type exhibiting higher expression of IFITM1 than the diffuse type (Figure 1C). High expression of IFITM1 was also observed for the intestinal type by Lauren's classification using immunohistochemical analysis in 151 patients with gastric cancer $(P=0.0070)$. Thus, IFITM1 expression clearly influences the development and progression of intestinal-type gastric cancer tumorigenesis. In addition, the appearance of IFITM1 in the inflammatory cells near the tumor regions suggests an inflammatory interaction between the tumor and its microenvironment induced by the inflammatory cytokines, as reported with colorectal cancer. ${ }^{30}$ Of note, IFITM1 was suggested to be a proinflammatory mediator induced by signaling from the activation of CD147 in macrophages. ${ }^{31}$ We compared the expression of IFITM1 with that of some inflammation markers in gastric cancer tissues. We found that IL-6, ${ }^{32}$ a potent pleiotropic inflammatory cytokine, and IL-8, ${ }^{33}$ a cytokine involved in gastric mucosa inflammation, were also highly expressed along with IFITM1. Although, for reasons we do not yet know, TNF- $\alpha$, a key molecule in chronic inflammatory diseases, ${ }^{34}$ was not expressed along with IFITM1 in gastric cancer tissues, we concluded that IFITM1-mediated inflammatory events contribute to tumor promotion and progression. Furthermore, the recent report that IFITM1 was up-regulated after $\mathrm{He}$ - 
licobacter pylori infection ${ }^{35}$ and the fact that tissue samples used in this study are mostly $H$. pylori positive (up to 90\%) suggest that IFITM1-mediated inflammatory events after $H$. pylori infection are a probable scenario for the progression of gastric cancer.

This study also found higher expression of histologically differentiated gastric carcinoma $(P=0.025)$. Although not statistically significant, probably because of the limited number of patients studied, patients with gastric cancer with moderate and marked expression of IFITM1 tended to show reduced survival rates. Taken together, the observations of association between IFITM1 expression and tumor invasion suggest that IFITM1 is a potential marker for poor prognosis in patients with gastric cancer, especially the intestinal type.

These studies attempted to elucidate the mechanisms regulating expression of the IFITM1 gene, which have not been identified to date. We conducted quantitative methylation analysis of $27 \mathrm{CpG}$ sites in the promoter-exon 1-intron 1 region. This analysis showed that methylation at $\mathrm{CpG}$ sites 11 to 26 ( -200 to 400 ) could be involved in the regulation of IFITM1 expression in gastric cancer cell lines. The findings of hypermethylation of promoter CpG sites in low IFITM1-expressing cells, hypomethylation in high IFITM1-expressing cells, recovery of IFITM1 expression on demethylation by 5-aza-dC treatment in gastric cancer cells (SNU-216, SNU-719, and MKN-28), and decreased IFITM1 expression by in vitro methylation indicate that IFITM1 expression is epigenetically regulated by DNA methylation, although further methylation studies of a broad range of patients are needed.

In addition, an interesting finding is that ETS and cyclin $\mathrm{D}$ binding myb-like transcription factor binding sites were predicted on $\mathrm{CpG}$ site 12. This finding suggests that $\mathrm{CpG}$ methylation of $\mathrm{CpG}$ site 12 may influence gastric cancer tumorigenesis by affecting oncogenic transcription factor binding. The proto-oncogene ETS factor is implicated in the pathogenesis of several types of cancers ${ }^{36,37}$ and in proinflammatory responses. ${ }^{38}$ Dmp1 encodes a DNA binding protein that receives signals from oncogenic Ras and, thus, functions as a tumor suppressor by activating the Arf-p53 pathway. ${ }^{39}$ Therefore, a valuable future issue to be addressed is the precise analysis of how and to what extent these transcription factor families cooperate and antagonize each other in promoter CpG methylation.

As a direct approach to clarify the involvement of IFITM1 in invasion and migration, we performed in vitro studies of the gain or loss of function studies. The results clearly showed that the suppression or up-regulation of IFITM1 expression significantly affected cancer cell migration and invasion, in agreement with recent reports of head and neck cancers ${ }^{18}$ and glioma. ${ }^{40}$ As noted by Fidler, ${ }^{41}$ metastasis involves sequential and selective steps so that IFITM1 may be involved in the initial step of invasion. Together with the results of survival analysis by the Kaplan-Meier plot, it is suggested that the migration and invasion of gastric cancer cells influenced by IFITM1 expression contributes to the rapid progression of malignancy.

The finding that IFITM1 expression is highly up-regulated in human gastric cancer and is involved in the migration and invasion of gastric cancer cells suggests a new target as a prognostic factor for gastric cancer. In addition, the observation that IFITM1 expression is regulated by DNA methylation of its promoter region may be useful to treat cancer. Further investigations are needed to elucidate the molecular mechanisms of IFITM1 and its role in the malignancy of gastric cancer.

\section{References}

1. Jemal A, Bray F, Center MM, Ferlay J, Ward E, Forman D: Global cancer statistics. CA Cancer J Clin 2011, 61:69-90

2. Crew KD, Neugut Al: Epidemiology of gastric cancer. World J Gastroenterol 2006, 12:354-362

3. Aburatani $\mathrm{H}$ : Discovery of a new biomarker for gastroenterological cancers. J Gastroenterol 2005, 40(Suppl 16):1-6

4. Economescu MC, Necula LG, Dragu D, Badea L, Dima SO, Tudor S, Nastase A, Popescu I, Diaconu CC: Identification of potential biomarkers for early and advanced gastric adenocarcinoma detection. Hepatogastroenterology 2010, 57:1453-1464

5. Lee HJ, Nam KT, Park HS, Kim MA, Lafleur BJ, Aburatani H, Yang HK, Kim WH, Goldenring JR: Gene expression profiling of metaplastic lineages identifies $\mathrm{CDH} 17$ as a prognostic marker in early stage gastric cancer. Gastroenterology 2010, 139:213-225e213

6. Huang YT, Heist RS, Chirieac LR, Lin X, Skaug V, Zienolddiny S, Haugen A, Wu MC, Wang Z, Su L, Asomaning K, Christiani DC: Genome-wide analysis of survival in early-stage non-small-cell lung cancer. J Clin Oncol 2009, 27:2660-2667

7. Gentles AJ, Plevritis SK, Majeti R, Alizadeh AA: Association of a leukemic stem cell gene expression signature with clinical outcomes in acute myeloid leukemia. JAMA 2010, 304:2706-2715

8. Germano S, Kennedy S, Rani S, Gleeson G, Clynes M, Doolan P, McDonnell S, Hughes L, Crown J, O'Driscoll L: MAGE-D4B is a novel marker of poor prognosis and potential therapeutic target involved in breast cancer tumorigenesis. Int J Cancer 2012, 130:1991-2002

9. Gaudet F, Hodgson JG, Eden A, Jackson-Grusby L, Dausman J, Gray JW, Leonhardt $\mathrm{H}$, Jaenisch R: Induction of tumors in mice by genomic hypomethylation. Science 2003, 300:489-492

10. Luczak MW, Jagodzinski PP: The role of DNA methylation in cancer development. Folia Histochem Cytobiol 2006, 44:143-154

11. Kurkjian C, Kummar S, Murgo AJ: DNA methylation: its role in cancer development and therapy. Curr Probl Cancer 2008, 32:187-235

12. Kwon OH, Park JL, Kim M, Kim JH, Lee HC, Kim HJ, Noh SM, Song KS, Yoo HS, Paik SG, Kim SY, Kim YS: Aberrant up-regulation of LAMB3 and LAMC2 by promoter demethylation in gastric cancer. Biochem Biophys Res Commun 2011, 406:539-545

13. Tomita H, Takaishi S, Menheniott TR, Yang X, Shibata W, Jin G, Betz KS, Kawakami K, Minamoto T, Tomasetto C, Rio MC, Lerkowit N, Varro A, Giraud AS, Wang TC: Inhibition of gastric carcinogenesis by the hormone gastrin is mediated by suppression of TFF1 epigenetic silencing. Gastroenterology 2011, 140:879-891

14. Evans SS, Lee DB, Han T, Tomasi TB, Evans RL: Monoclonal antibody to the interferon-inducible protein Leu-13 triggers aggregation and inhibits proliferation of leukemic B cells. Blood 1990, 76:2583-2593

15. Evans SS, Collea RP, Leasure JA, Lee DB: IFN-alpha induces homotypic adhesion and Leu-13 expression in human B lymphoid cells. J Immunol 1993, 150:736-747

16. Deblandre GA, Marinx OP, Evans SS, Majjaj S, Leo O, Caput D, Huez GA, Wathelet MG: Expression cloning of an interferon-inducible 17$\mathrm{kDa}$ membrane protein implicated in the control of cell growth. J Biol Chem 1995, 270:23860-23866

17. Brass AL, Huang IC, Benita Y, John SP, Krishnan MN, Feeley EM, Ryan BJ, Weyer JL, van der Weyden L, Fikrig E, Adams DJ, Xavier RJ, Farzan M, Elledge SJ: The IFITM proteins mediate cellular resistance to influenza $\mathrm{A} \mathrm{H} 1 \mathrm{~N} 1$ virus, West Nile virus, and dengue virus. Cell 2009, 139:1243-1254

18. Hatano $H$, Kudo $Y$, Ogawa I, Tsunematsu T, Kikuchi A, Abiko $Y$, Takata T: IFN-induced transmembrane protein 1 promotes invasion at early stage of head and neck cancer progression. Clin Cancer Res 2008, 14:6097-6105 
19. Fumoto S, Shimokuni T, Tanimoto K, Hiyama K, Otani K, Ohtaki M, Hihara J, Yoshida K, Hiyama E, Noguchi T, Nishiyama M: Selection of a novel drug-response predictor in esophageal cancer: a novel screening method using microarray and identification of IFITM1 as a potent marker gene of CDDP response. Int J Oncol 2008, 32:413-423

20. Johnatty SE, Beesley J, Chen X, Macgregor S, Duffy DL, Spurdle AB, et al: Evaluation of candidate stromal epithelial cross-talk genes identifies association between risk of serous ovarian cancer and TERT, a cancer susceptibility "hot-spot." PLoS Genet 2010, 6:e1001016

21. Gomes AQ, Correia DV, Grosso AR, Lanca T, Ferreira C, Lacerda JF, Barata JT, Silva MG, Silva-Santos B: Identification of a panel of ten cell surface protein antigens associated with immunotargeting of leukemias and lymphomas by peripheral blood $\gamma \delta$ T cells. Haematologica 2010, 95:1397-1404

22. Pan Z, Chen S, Pan X, Wang Z, Han H, Zheng W, Wang X, Li F, Qu S Shao R: Differential gene expression identified in Uigur women cervical squamous cell carcinoma by suppression subtractive hybridization. Neoplasma 2010, 57:123-128

23. Yang Y, Lee JH, Kim KY, Song HK, Kim JK, Yoon SR, Cho D, Song KS, Lee $\mathrm{YH}$, Choi I: The interferon-inducible 9-27 gene modulates the susceptibility to natural killer cells and the invasiveness of gastric cancer cells. Cancer Lett 2005, 221:191-200

24. Rho HW, Lee BC, Choi ES, Choi IJ, Lee YS, Goh SH: Identification of valid reference genes for gene expression studies of human stomach cancer by reverse transcription-qPCR. BMC Cancer 2010, 10:240

25. Goh SH, Hong SH, Lee BC, Ju MH, Jeong JS, Cho YR, Kim IH, Lee YS: elF3m expression influences the regulation of tumorigenesisrelated genes in human colon cancer. Oncogene 2011, 30:398-409

26. Sobin LH, Wittekind C: TNM Classification of Malignant Tumors, ed 6. New York, Wiley-Liss Inc., 2002

27. Andreu P, Colnot S, Godard C, Laurent-Puig P, Lamarque D, Kahn A, Perret C, Romagnolo B: Identification of the IFITM family as a new molecular marker in human colorectal tumors. Cancer Res 2006, 66:1949-1955

28. Chattopadhyay I, Phukan R, Singh A, Vasudevan M, Purkayastha J, Hewitt S, Kataki A, Mahanta J, Kapur S, Saxena S: Molecular profiling to identify molecular mechanism in esophageal cancer with familial clustering. Oncol Rep 2009, 21:1135-1146
29. Gyorffy B, Dietel M, Fekete T, Lage H: A snapshot of microarraygenerated gene expression signatures associated with ovarian carcinoma. Int J Gynecol Cancer 2008, 18:1215-1233

30. Klampfer L: Cytokines, inflammation and colon cancer. Curr Cancer Drug Targets 2011, 11:451-464

31. Kim JY, Kim H, Suk K, Lee WH: Activation of CD147 with cyclophilin A induces the expression of IFITM1 through ERK and PI3K in THP-1 cells. Mediators Inflamm 2010, 2010:821940

32. Ishihara K, Hirano T: IL-6 in autoimmune disease and chronic inflammatory proliferative disease. Cytokine Growth Factor Rev 2002, 13: 357-368

33. Andersen LP, Holck S, Janulaityte-Gunther D, Kupcinskas L, Kiudelis G, Jonaitis L, Janciauskas D, Holck P, Bennedsen M, Permin H, Norn $\mathrm{S}$, Wadstrom T: Gastric inflammatory markers and interleukins in patients with functional dyspepsia, with and without Helicobacter pylori infection. FEMS Immunol Med Microbiol 2005, 44:233-238

34. Mocellin S, Rossi CR, Pilati P, Nitti D: Tumor necrosis factor, cancer and anticancer therapy. Cytokine Growth Factor Rev 2005, 16:35-53

35. Hofman VJ, Moreilhon C, Brest PD, Lassalle S, Le Brigand K, Sicard D, Raymond J, Lamarque D, Hebuterne XA, Mari B, Barbry PJ, Hofman PM: Gene expression profiling in human gastric mucosa infected with Helicobacter pylori. Mod Pathol 2007, 20:974-989

36. Oikawa T, Yamada T: Molecular biology of the Ets family of transcription factors. Gene 2003, 303:11-34

37. Seth $A$, Watson DK: ETS transcription factors and their emerging roles in human cancer. Eur J Cancer 2005, 41:2462-2478

38. Feng W, Xing D, Hua P, Zhang Y, Chen YF, Oparil S, Jaimes EA: The transcription factor ETS-1 mediates proinflammatory responses and neointima formation in carotid artery endoluminal vascular injury. Hypertension 2010, 55:1381-1388

39. Sugiyama T, Frazier DP, Taneja P, Morgan RL, Willingham MC, Inoue $\mathrm{K}$ : Role of DMP1 and its future in lung cancer diagnostics. Expert Rev Mol Diagn 2008, 8:435-447

40. Yu F, Ng SS, Chow BK, Sze J, Lu G, Poon WS, Kung HF, Lin MC: Knockdown of interferon-induced transmembrane protein 1 (IFITM1) inhibits proliferation, migration, and invasion of glioma cells. J Neurooncol 2011, 103:187-195

41. Fidler IJ: Critical factors in the biology of human cancer metastasis: twenty-eighth G.H.A. Clowes memorial award lecture. Cancer Res 1990, 50:6130-6138 